\title{
Comparing total hip arthroplasty and hemiarthroplasty for the treatment of displaced femoral neck fracture in the active elderly over 75 years old: a systematic review and meta-analysis of randomised control trials
}

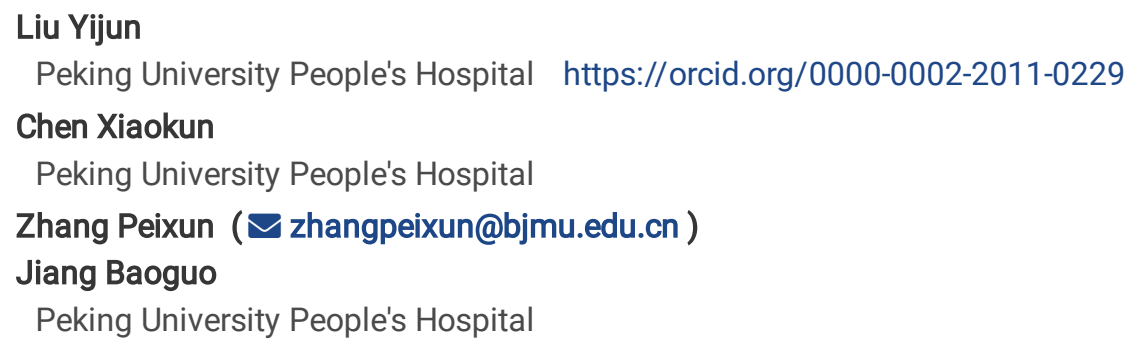




\section{Abstract}

Background: Displaced femoral neck fractures (DFNF) are increasingly common in elderly patients. Repair of DFNF can be completed using two methods, hemiarthroplasty (HA) or total hip Arthroplasty (THA). However, there is much controversy regarding whether HA or THA is superior in active elderly patients over 75 years old. Methods: We conducted the literature search by searching PubMed, Embase, the Cochrane Library, ClinicalTrials.gov, and Web of Science from the inception dates to June 1, 2019. Randomised controlled trials (RCT) were included according to the inclusion and exclusion criteria. Included studies were analysed according to Cochrane review methods. Results: Nine studies met the inclusion criteria totalling 631 participants (301 THA and 330 HA囚. Four of the studies conducted were identical to a previous study but look at different follow up measures. The analysis of previously collected data revealed that the THA group had a lower erosion rate, higher total pain and function HHS, and higher EQ-5Dindex. The re-operation rate was significantly lower in the THA group after five years of follow up after adding the patients with painful symptoms to the group of patients revised. However, THA had longer operative time and a higher dislocation rate in the first three years compared to the HA procedure. Moreover, there was an insignificant difference in mortality rate, general complications, wound infection, duration of hospital stay, and VTE prevalence among the two procedures. Conclusions: THA may be a preferred management option for active elderly patients over 75 years old, after careful evaluation of patients' general condition and tolerance of surgery. Strict management and follow up protocols should be followed to prevent dislocation within the first three years following a THA. Trial registration: This study was registered at the International Prospective Register of Systematic Reviews (CRD42019139135). The date of registration is 16-062019. Keywords: displaced femoral neck fractures; total hip arthroplasty; hemiarthroplasty;

\section{Background}

Hip fractures are a worldwide health problem, with the incidence of hip fractures increasing over time. The increasing incidence of hip fractures can be attributed to increases in the elderly population and improvements in life expectancy due to modern medicine[1]. The prevalence of hip fractures in Asian countries will rise from over 1 million per year in 1990 to over 6 million by 2050[2]. The residual lifetime risk of suffering a hip fracture is about $5.6 \%$ for men and $20 \%$ for women[3]. Hip fractures are a leading cause of disability worldwide and contribute to both morbidity and mortality in the elderly population, contributing to the increasing costs of health care[4]. Hip fractures are mainly divided into two subtypes, inter-trochanteric fractures and femoral neck fractures (FNF).

The treatments for FNF patients include internal fixation, $\mathrm{HA}$, or THA[5]. Factors that determine the treatment plan for the patient include age, physical condition, surgeon preference, pre-injury activity level, functional demand and cognitive status.

Internal fixation is a preferred management option for young people or the elderly who are intolerant of prosthesis surgery[6]. THA and HA are widely used in the displaced femoral neck fractures (DFNF)[5]. HA has advantages of shorter operation times, less blood loss, less technical demand, less economic burden, and a lower post-operative dislocation rate[7-10]. THA procedures are associated with better hip function, less acetabulum erosion, and a lower revision rate, but more substantial surgical strike and a higher post-operative dislocation rate[7-11].

With improvements in daily living standards and modern medical practices, today's elderly have a longer life expectancy and therefore, a higher demand for adequate hip function. These increased demands for hip function may lead to a higher risk of acetabulum erosion after arthroplasty[12]. These factors seem to favour the THA procedure. However, patients over 75 years have lower surgical tolerance. As a result of the increased surgical risks and lower function demands, it is hard to determine if the benefits of THA outweigh the risks in this population[13].

The clinical practice published in the New England journal of medicine suggested that THA should be selected in cognitively intact and ambulating independent patients over 60 years old, but there was no subgroup analysis on age[5]. Current guidelines from the American Academy of Orthopedic Surgeons indicate that THA would provide greater benefit in selected patients because of lower pain and lower revision rates. However, treatment planning for patients with lower function demands or those with poor preoperative donations is not straight forward[14]. Current guidelines from the National Institute for Health and Clinical Excellence (NICE) in the UK recommend to perform THA to patients who can walk independently, not cognitively impair and medically fit for the procedure. However, the definition of medically fit was not clear[15]. A study found that only $32 \%$ of patients who satisfied the NICE guidelines received THA. The variable with most important was age with a cut off at 76[13].

An international survey found that $73 \%$ of the surgeons preferred HA in DFNF patients between $60-80$ years old[16]. A study using a large dataset indicated that HA was associated with better survivorship in patients over 75 years old[17], and another recent study 
found that the frequency of HA procedures increase as age increases. However, in recent years, the utilisation of THA to treat DFNF has increased in the elderly population[18]. A systematic review and meta-analysis recommended THA in patients younger than 80 years old or those with a life expectancy of more than four years[10]. The findings of this systematic review were similar to other previously performed studies[19-21].

Moreover, Two RCTs with a 9-year and 12-year follow up found that there were no statistical differences in the functional outcomes, revision rates, and complication rates between HA and THA treatments for active elderly patients over 70 years old[22, 23]. There is currently an ongoing RCT comparing THA and HA outcomes for DFNF in patients over 80 years old, but it is yet to be finished[12].

The option of arthroplasty in DFNF patients over 75 years old becomes more and more critical as the elderly continue to face greater demands. The previous meta-analyses did not include strict age restrictions and some of these studies also included patients who were unable to walk independently or received a polycarbonate-urethane (PCU) THA that would lead to high heterogeneity, therefore making it complicated to apply these findings to patients with older age $[9,10,19,24-26]$. The purpose of this study is to evaluate the clinical outcomes of THA and HA in the treatment of DFNF in the active elderly over 75 years old by using the latest evidence from previously performed RCTs.

\section{Methods}

This systematic review and meta-analysis was performed according to the Systematic Reviews and Meta-Analyses (PRISMA) statement[27, 28]. This study was registered at the International Prospective Register of Systematic Reviews (CRD42019139135). The date of registration is 16-06-2019.

\section{Search strategy}

We conducted the literature search by searching PubMed, Embase, the Cochrane Library, ClinicalTrials.gov, and Web of Science from the inception dates to June 1, 2019. Other search methods included a manual search using the references in relevant articles and abstracts of related meetings, and personal communication with experts in the field. We applied no language restrictions. We used the following combined texts and MeSH terms: femoral neck fractures, hemiarthroplasty, total hip arthroplasty, RCT, and entry terms.

\section{Inclusion and exclusion criteria}

RCTs were regarded as eligible if they met the inclusion criteria: (1) trials enrolling elderly patients and mean age $>75$ years old, $₫ 2 \otimes$ trials enrolling community-ambulant patients, (3) trials enrolling DFNF (Garden III, IV), (4) trials comparing THA and HA. Exclusion criteria were as follows; (1) bedridden or immobile patients, (2) patients with advanced radiological osteoarthritis or rheumatoid arthritis in the fractured hip, (3) patients with pathological fractures secondary to malignant disease.

Two independent investigators (L.Y.J, C.X.K) reviewed the titles and abstracts of the search results for trail selection. If there was insufficient information to determine if the study should be selected, investigators read the full-text for further assessment. Data extraction was also performed by these two investigators (L.Y.J, C.X.K). Any disagreements were resolved by a third independent investigator(Z.P.X). We assessed the risk of bias according to the Cochrane risk-of-bias criteria[27]. We defined the other bias as not enough detailed description of materials, methods, and results, not similar in baseline characteristics, and sponsored by companies.

\section{Outcome measures}

We extracted the following information from each study: lead author, participant characteristics, follow up duration, details of the interventions, the primary outcomes, and secondary outcomes. The primary outcomes measured were intra-operative details (blood loss and duration of operation), mortality, functional outcomes (Harris Hip Score), re-operation rates, dislocation rates, erosion rates, infection rates, deep venous thrombosis prevalence, and general complication rates. The secondary outcomes were prosthesis loosening, peri-prosthetic fractures, Europol (EQ) index-5D score and the duration of hospital stay.

\section{Statistical analysis}

We used both the Q2 test and $\mathrm{I}^{2}$ test to assess the statistical heterogeneity among studies. If the P value resulting from the Q2 test was $\nabla 0.1$ or the value of $\mathrm{I}^{2}$ test was $>50 \%$, it was indicative of statistical heterogeneity. We calculated the RR (relative risks) for dichotomous outcomes, and weight mean difference or standardised mean difference for continuous outcomes with corresponding $95 \%$ confidence 
intervals $(\mathrm{Cl})$. The results were pooled by a fixed effects model. If data was indicative of statistical heterogeneity, a random effects model was applied instead. If two studies were based on the same population, only the latter one was included in the forest plot. We performed the sensitivity analysis by excluding research to evaluate the stability of the results. We used the Cochrane Review Manager 5.3 software for data analysis and $\mathrm{P}<0.05$ was considered to be statistically significant.

\section{Results:}

\section{Study Characteristics}

We identified 2186 studies, of which nine studies met the inclusion criteria[8, 20, 22, 23,29-33]. Four of them were the same as one of the studies, but with different follow-up[23, 30, 31, 33] (Fig. 1). During study selection, we excluded some RCTs, including five studies that incorporated patients younger than 75 years old[7, 34-37] and two studies included patients unable to live independently[38,39], and two studies included patients unable to live independently[40,41]. There were a total of 631 participants in the nine trials included in the study. Of these, 301 patients underwent a THA procedure, and 330 patients underwent a HA procedure. The nine trials were published between 2006 and 2017 (Table 1). The range of the duration of follow up was from 24.0 months to 194.0 months. One of these studies also included a third arm (internal fixation), but the data from these arms were not taken into account[32].

\section{Risk of bias assessment}

All nine Randomized Controlled Trials were assessed and found to have used adequate randomisation procedures, including the sealedenvelope technique, computer randomisation programs, and systemic random sampling[8,20,22, 23, 29-33]. Only one of the studies utilised blinding of outcome measurements, which had the interviewers blinded to the patient recruitment and randomisation or the type of surgery performed[32]. There was no blinding of participants in any of the included studies. Four of the studies were multi-centre studies[22, 23, 30,32]. One of the studies was funded by a commercial entity[20]. The results of the risk of bias assessment were summarized in Fig.2.

\section{Operative time}

Three studies assessed the operative time in both the THA and the HA groups (117 with THA and 123 with HA)[20, 22, 30]. The operative time was significantly longer in the THA group (MD 18.20, 95\% $\mathrm{Cl}$ 9.99-26.41, Fig.3) and heterogeneity across the studies was $46 \%$.

\section{Study Characteristics}

We identified 2186 studies, of which nine studies met the inclusion criteria[8, 20, 22, 23, 29-33]. Four of them were the same as one of the studies, but with different follow-up[23, 30, 31, 33] (Fig. 1). During study selection, we excluded some RCTs, including five studies that incorporated patients younger than 75 years old[7, 34-37] and two studies included patients unable to live independently[38, 39], and two studies included patients unable to live independently[40,41]. There were a total of 631 participants in the nine trials included in the study. Of these, 301 patients underwent a THA procedure, and 330 patients underwent a HA procedure. The nine trials were published between 2006 and 2017 (Table 1). The range of the duration of follow up was from 24.0 months to 194.0 months. One of these studies also included a third arm (internal fixation), but the data from these arms were not taken into account[32].

\section{Risk of bias assessment}

All nine Randomized Controlled Trials were assessed and found to have used adequate randomisation procedures, including the sealedenvelope technique, computer randomisation programs, and systemic random sampling[8,20,22, 23, 29-33]. Only one of the studies utilised blinding of outcome measurements, which had the interviewers blinded to the patient recruitment and randomisation or the type of surgery performed[32]. There was no blinding of participants in any of the included studies. Four of the studies were multi-centre studies[22, 23, 30,32]. One of the studies was funded by a commercial entity[20]. The results of the risk of bias assessment were summarized in Fig.2.

\section{Operative time}

Three studies assessed the operative time in both the THA and the HA groups (117 with THA and 123 with HA)[20, 22, 30]. The operative time was significantly longer in the THA group (MD 18.20, 95\% $\mathrm{Cl}$ 9.99-26.41, Fig.3) and heterogeneity across the studies was 
$46 \%$.

\section{General complication}

Four studies assessed the general complication rates in both groups ( 261 with THA and 289 with HA), with the mean follow up being $14.5 \mathrm{~m}[20,23,30,32]$. Although the HA group had lower rates of general complications, there was no significant difference from the THA group (RR 1.38, 95\% Cl 0.86-2.21, Fig.5), There was low heterogeneity $\left(\mathrm{I}^{2}=0 \%\right)$ among the studies.

\section{Wound Infection}

Three studies assessed the wound infection rates of both groups (169 with THA and 170 with HA)[20, 22, 32]. Pooling the data of the included studies elicited no significant statistical difference between the THA and HA groups (RR 1.54, 95\% CI 0.54-4.41, Fig.6), and heterogeneity across the studies was $0 \%$.

\section{VTE}

Three studies assessed the venous thromboembolism (VTE) prevalence in both groups (169 with THA and 170 with HA) with the mean follow up of $9.66 \mathrm{~m}[20,22,32]$. No significant difference was found between the groups (RR 1.80, 95\% CI 0.61-5.3, Fig.7). There was low heterogeneity $\left(\mathrm{I}^{2}=6 \%\right)$ among studies.

\section{Peri-prosthetic fracture}

Two studies assessed the rate of peri-prosthetic fracture in both groups (82 with THA and 82 with HA)[20, 22]. There was no significant statistical difference between both groups (RR $0.59,95 \% \mathrm{Cl} 0.08-4.60$, Fig.8) and no significant between-study heterogeneity $\left(\mathrm{I}^{2}=0 \%\right.$ ).

\section{Erosion}

Three studies reported the erosion rates in both groups (189 with THA and 202 with HA) during the follow up periods (mean 45.3m)[20, 22 , 23]. The erosion rates were $0.48 \%$ in the THA group and $13.7 \%$ in the HA group with a significant difference (RR $0.05,95 \%$ CI 0.01 0.20 , Fig.9) and no significant between-study heterogeneity $\left(\mathrm{I}^{2}=0 \%\right)$.

\section{Re-operation rate}

Four studies assessed the relative risk of re-operation rate in both two groups (375 with THA versus 396 with HA)[20, 22, 23, 32]. We divided the data into two subgroups according to follow up durations (within five years and more than five years). Four studies assessed the re-operation rate within five years of follow up $\nabla 1^{2}=0 \% \otimes[20,22,23,32]$. Pooling the data revealed no significant difference (RR 1.12, 95\% Cl 0.49-2.54, Fig.10) in outcomes between the THA and HA groups. Two studies assessed the re-operation rate after five

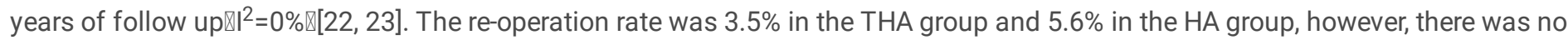
significant difference (RR $0.45,95 \% \mathrm{Cl} 0.14-1.39$, Fig. 10) between the two techniques. If we added the patients with painful symptoms to the group of patients revised, the re-operation rate was significantly lower in the THA group after five years of follow up than in the HA group (RR 0.26, 95\%Cl 0.09-0.82, Fig.11). Heterogeneity across the studies was 0\%[22, 23].

\section{Dislocation rate}

Five studies reported the dislocation rate in both groups (301 with THA and 300 with HA). We divided the data into three subgroups according to follow up duration $₫$ within three years and more than three years $₫[20,22,23,30,32]$. There was a significant statistical difference between dislocation rates in the THA group $₫ 4.0 \%)$ and the HA group $₫ 0.61 \% \varangle(\mathrm{RR} 4.40,95 \% \mathrm{Cl} 1.35-14.37$, Fig.12). There were no dislocations reported in the subgroups that had more than three years of follow up[20, 23].

\section{Total HHS}

Three studies assessed the total Harris Hip Score (HHS) in both groups (190 with THA and 218 with HA)[20, 23, 30]. We divided the data into two subgroups according to the follow up duration (within one year and more than one year). Two studies assessed the total HHS within 1 year $\nabla \mathrm{I}^{2}=0 \% \varangle[20,30]$. Pooling the data showed a significantly higher total HHS in the THA group compared to the HA group (MD 4.63, 95\% Cl 0.44-8.82, Fig.12). Two studies assessed the total HHS after more than one year of follow up ( $\left.\mathrm{I}^{2}=32 \%\right)$, and the data favoured the THA group (MD 5.00, 95\% Cl 1.74-8.26, Fig.12)[20, 30]. 


\section{Pain HHS}

Two studies assessed the HHS pain in both groups (175 with THA and 197 with HA)[20, 23]. We divided the data into two subgroups according to the follow up duration (within one year and more than one year). Two studies assessed the HHS pain within one year $\triangle \mathrm{I}^{2}=0 \% \bigotimes[20,23]$. Patients in the THA group experienced significantly less pain than patients in the HA group (MD 2.28, 95\% $\mathrm{Cl} 0.93-3.64$. Fig.13). Two studies assessed the HHS pain after more than one year of follow up $\left(1^{2}=84 \%\right)$, and the data favoured the THA group (MD $3.09,95 \%$ Cl 1.78-4.40, Fig.13)[20, 23].

\section{Function HSS}

Two studies assessed the HHS function in both groups (171 with THA and 192 with HA)[20, 23]. We divided the data into two subgroups according to the follow up duration (within one year and more than one year). Two studies assessed the HHS function within one year $\ \mathrm{I}^{2}=56 \%$ ) and the data tended to favour the THA group (MD 1.37, 95\% Cl-1.54-4.27, Fig,14)[20, 23]. Two studies assessed the HHS function after more than one year of follow up $\left(\mathrm{I}^{2}=0 \%\right)$, and the data favoured the THA group ( $\mathrm{MD} 3.48,95 \% \mathrm{Cl}-0.7-$ 6.26 , Fig, 14) [20, 23].

\section{Eq-5 $\mathrm{D}_{\text {index }}$}

Two studies assessed the Eq-5D in both groups with a mean follow up duration of 18m (122 with THA and 120 with HA)[20, 32]. THA group had better Eq-5D $\mathrm{D}_{\text {index }}$ score (MD $0.13,95 \% \mathrm{Cl} 0.03-0.22$, Fig. 15$)$. There was no significant heterogeneity $\left(I^{2}=3 \%\right)$.

\section{Hospital stay}

Two studies assessed the length of hospital stay in both groups (132 with THA and 160 with HA). The data trended to favour the HA group (MD 1.30, 95\% Cl -0.43-4.57, Fig.16)[23, 30]. Heterogeneity across the studies was $0 \%$.

\section{Discussion}

DFNF patients over 75 years old can be adequately managed with THA or HA procedures, but previous studies have yet to demonstrate the superiority of one method over the other in this population[ $[9,10,19,20,22-26,30,32]$. Our study revealed that the THA group had lower erosion rates, increased pain HHS, total HHS, function HHS and EQ-5Dindex. There was no significant difference between two groups in the re-operation rate. If we added the patients with painful symptoms to the re-operation group, the re-operation rate would be significantly lower in the THA group after five years of follow up. The function HHS was better in the THA group after one year of follow up. However, the THA group had a longer average operative time. The dislocation rate was higher within three years in the THA group. The general complication rates, mortality rates from one to five years and duration hospital stays favoured the HA group but without significant difference. Moreover, there was no significant difference in postoperative infection, peri-prosthetic fractures or VTE prevalence between the two groups.

Compared to other systematic reviews and meta-analyses[9, 10, 19, 24-26], our study limited patients' age to greater than 75 years old, which was more specific than the previous studies. We excluded two RCTs because they included patients with compromised mental states[38, 39], and two RCTs because they used a THA procedure utilising a polycarbonate-urethane (PCU) acetabulum. The PCU components utilised in these studies were pliable, and therefore may have increased the erosion rates and negatively affected stability. This method also led to differences in operative time, hip function and complication rates between PCU-THA and traditional THA[40, 41].

Re-operation criteria included different procedure, such as debridement, internal fixation, and revision. Some studies suggested that reoperation rates were higher in the HA groups compared to the THA groups [9, 10, 19, 22, 25, 26]. Avery et al. [22] performed an RCT with nine years follow up and found that $75 \%$ of the revisions of HA were due to acetabular wear and erosion. However, studies contained in the Australian and Italian national registries identified HA to have lower re-operation rates than THA in patients exclusively over 75 years old[17]. Our trial found no significant difference in re-operation rate between the two groups in patients over 75 years old. The failure to find a difference may be the result of the fact that patients included in this study were older and had lower levels of baseline activity as well as lower tolerance to re-operation. After adding in the patients with painful symptoms, the re-operation rate was significantly lower in the THA group after five years follow up, which indicated that patients in THA group had a better quality of life five years post operation. 
Many studies $[9,10,22-26]$ found that dislocation rates were higher among the THA group, which correlated to the surgical approach and the femoral head size. However, some studies $[9,10,22,23]$ suggested that there might be no significant differences in dislocation rates several years after the operation. Avery et al. [22] performed an RCT with nine years follow up and found that all dislocations in the THA group occurred within one month on the initial surgery. Tol et al. [23] found no dislocations in either group at a mean follow up of 12 years. Feng Wang et al. [9] and Daniel P. Lewis et al. [10] found that there was no significant difference in dislocation rates after four years of follow up. Our trial found that dislocation rates were higher within the first three years for the THA group. However, no dislocations occurred in the 133 patients included in the subgroup with follow up of more than three years (mean $96 \mathrm{~m}$ ), which was different from the data published in other META-analyses[24-26]. Patients in this study were older with less functional demand and lower levels of activity, both of which most likely contributed to a lower dislocation rate. Secondly, dislocation might be a risk factor for mortality in patients over 75 years, and only patients without dislocation could be still alive after long term follow up (mean $96 \mathrm{~m})$. This hypothesis is consistent with a previous RCT [23].

Our trial found that the THA group had better HHS outcomes. These results were consistent with previously completed meta-analyses. However, these analyses did not have similar inclusion criteria that restricted the studies to patients over 75 years old and had different inclusion criteria[19, 24]. Daniel P. et al. [10] came to a different conclusion which stated that there was no significant difference in total HHS and pain HHS between the two groups in patients over 80 years old. However, Daniel P. et al. included some RCTs using PCU-THA, which might have led to high heterogeneity. Our trial found that the THA group had better pain HHS after one year of follow up, but heterogeneity across the studies was high. Two RCTs[20, 23, 24] had similar inclusion criteria, patients' characteristics, and prosthesis types. The heterogeneity among our studies might be due to other factors such as the differences in surgical technique, recovery programs and so on. In similar meta-analyses $[9,10]$, heterogeneity among studies in HHS was also high. Our trial found that THA had better pain HHS within one year follow up. However, the functional HHS was higher in the THA group only after one year. It indicated that patients could have the advantage of less pain in THA soon after the operation, but that it took a longer time to achieve the improvement in walking and living ability. The EQ-5D was higher in the THA group with a mean follow up of $18 \mathrm{~m}$. It indicated that although patients over 75 had lower baseline levels of activity, the improvement of hip function by THA could vastly improve the quality of life for patients. The differences in hip function between the two groups are still controversial in terms of long-term follow up. Yiqiong Zhao et al. [19] indicated that HA had worse HHS, because of a higher rate of acetabular wear, which leads to pain and even revision procedures. An RCT with a mean follow-up of 13 years found better HHS in the THA group[38]. However, TOL et al. [23] and Avery et al. [22] both found no significant difference in HHS between the two groups at a mean follow up of twelve years and nine years. Our trial found increased pain HHS, total HHS, function HHS in THA group after 1 year of follow up, but it did not have adequate data to analyse the hip function of long-term follow up.

Limitations within our study included the use of a small number of studies because of the inclusion criteria, and as a result, some essential data endpoints (average blood loss and long term HHS) could not be analysed. Secondly, nearly all the included studies[20, $22,23,30$ ] had defects in the procedure for the blinding of participants and outcome assessment, which may have skewed the results. Thirdly, we could only perform subgroup analyses according to age in order to determine surgical tolerability because included studies did not classify patients according to important characteristics such as comorbidities and ASA scores. Fourthly, included studies were published between 2006 and 2017, and during this period, there were many advancements in orthopaedics, such as prosthetic equipment, surgical techniques and hip function evaluation methods. These developments may have led to high heterogeneity in HHS results and limited the capability to analyse the data in regards to important indexes, such as Short-Form 36 and the Oxford hip score. In the future, further reviews are needed after more RCTs[12] are completed in order to understand better what the preferred management option should be.

\section{Conclusions}

For active elderly patients over 75 years old, the more substantial surgical impact of a THA will not lead to increases in the mortality rate, general complication rate, wound infection rate, duration of hospital stay or VTE prevalence. Moreover, THA is capable of returning patients to a higher level of hip function and quality of life with lower rates of acetabular erosion. These findings suggest that THA may be a preferred management option for active elderly patients over the age of 75 years. Each patient must be carefully evaluated to assess their general condition and tolerance to the procedure, and there must be a strong network of follow up and management to prevent dislocation within the first three years following the procedure.

\section{Abbreviations}


FNF: Femoral Neck Fractures

DFNF囚Displaced Femoral Neck Fractures

NICE: National Institute for Health and Clinical Excellence

HHS: Harris Hip Score

Eq-5D: Europol index-5D

RR: Relative Risks

Cl: Confidence intervals

VTE: Venous Thromboembolism

PCU: Polycarbonate-Urethane

\section{Declarations}

Ethics approval and consent to participate: Not applicable.

Consent for publication: Not applicable.

Availability of data and materials: The datasets and materials are available from corresponding authors on reasonable request.

Competing interests: The authors declare that they have no competing interests

Funding: 1.Innovation team project of Ministry of Education $₫$ NO.IRT-16R01囚: 2112000004. 2. Key Laboratory of Trauma and Neural Regeneration (Peking University). Ministry of Education. 区No.BMU2019XY007-01区:127000160.

Authors' contributions: LYJ and CXK performed the literature search, reviewed the literature and wrote the manuscript. ZPX and JBG contributed to the collected the data, edited the manuscript and guaranteed the integrity of the entire study.

Acknowledgements: I appreciated Dr Lin for her support and understanding.

\section{References}

1. Hagino H, Katagiri H, Okano T, Yamamoto K, Teshima R: Increasing incidence of hip fracture in Tottori Prefecture, Japan: trend from 1986 to 2001. Osteoporos Int 2005, 16(12):1963-1968.

2. Cooper C, Campion G, Melton LJ, 3rd: Hip fractures in the elderly: a world-wide projection. Osteoporos Int 1992, 2(6):285-289.

3. Lau EM, Cooper C, Wickham C, Donnan S, Barker DJ: Hip fracture in Hong Kong and Britain. Int J Epidemio/ 1990, 19(4):1119-1121.

4. Cummings SR, Rubin SM, Black D: The future of hip fractures in the United States. Numbers, costs, and potential effects of postmenopausal estrogen. Clinical orthopaedics and related research 1990(252):163-166.

5. Bhandari M, Swiontkowski M: Management of Acute Hip Fracture. N Engl J Med 2017, 377(21):2053-2062.

6. Parker MJ, Khan RJ, Crawford J, Pryor GA: Hemiarthroplasty versus internal fixation for displaced intracapsular hip fractures in the elderly. A randomised trial of 455 patients. The Journal of bone and joint surgery British volume 2002, 84(8):1150-1155.

7. Sonaje JC, Meena PK, Bansiwal RC, Bobade SS: Comparison of functional outcome of bipolar hip arthroplasty and total hip replacement in displaced femoral neck fractures in elderly in a developing country: a 2-year prospective study. European journal of orthopaedic surgery \& traumatology : orthopedie traumatologie 2018, 28(3):493-498.

8. van den Bekerom MP, Hilverdink EF, Sierevelt IN, Reuling EM, Schnater JM, Bonke H, Goslings JC, van Dijk CN, Raaymakers EL: A comparison of hemiarthroplasty with total hip replacement for displaced intracapsular fracture of the femoral neck: a randomised controlled multicentre trial in patients aged 70 years and over. The Journal of bone and joint surgery British volume 2010, 92(10):1422-1428. 
9. Wang F, Zhang H, Zhang Z, Ma C, Feng X: Comparison of bipolar hemiarthroplasty and total hip arthroplasty for displaced femoral neck fractures in the healthy elderly: a meta-analysis. BMC musculoskeletal disorders 2015, 16:229.

10. Lewis DP, Waever D, Thorninger R, Donnelly WJ: Hemiarthroplasty vs Total Hip Arthroplasty for the Management of Displaced Neck of Femur Fractures: A Systematic Review and Meta-Analysis. The Journal of arthroplasty 2019, 34(8):1837-1843.e1832.

11. Bhandari M, Einhorn TA, Guyatt G, Schemitsch EH, Zura RD, Sprague S, Frihagen F, Guerra-Farfan E, Kleinlugtenbelt YV, Poolman RW et al: Total Hip Arthroplasty or Hemiarthroplasty for Hip Fracture. N Engl J Med 2019.

12. Skoldenberg O, Chammout G, Mukka S, Muren O, Nasell H, Hedbeck CJ, Salemyr M: HOPE-trial: hemiarthroplasty compared to total hip arthroplasty for displaced femoral neck fractures in the elderly-elderly, a randomized controlled trial. BMC musculoskeletal disorders 2015, 16:307.

13. Perry DC, Metcalfe D, Griffin XL, Costa ML: Inequalities in use of total hip arthroplasty for hip fracture: population based study. BMJ (Clinical research ed) 2016, 353:i2021.

14. listed. Na: Management of Hip Fractures in the Elderly: Evidence-Based Clinical Practice Guideline. 2014. American Academy of Orthopaedic Surgeons (AAOS). https://wwwaaosorg/cc_files/aaosorg/research/guidelines/hipfxguideline pdf (date last accessed 5 October 2018) 2014.

15. Ftouh S, Morga A, Swift C: Management of hip fracture in adults: summary of NICE guidance. BMJ (Clinical research ed) 2011, 342:d3304.

16. Bhandari M, Devereaux PJ, Tornetta P, 3rd, Swiontkowski MF, Berry DJ, Haidukewych G, Schemitsch EH, Hanson BP, Koval K, Dirschl $\mathrm{D}$ et al: Operative management of displaced femoral neck fractures in elderly patients. An international survey. The Journal of bone and joint surgery American volume 2005, 87(9):2122-2130.

17. Kannan A, Kancherla R, McMahon S, Hawdon G, Soral A, Malhotra R: Arthroplasty options in femoral-neck fracture: answers from the national registries. International orthopaedics 2012, 36(1):1-8.

18. Harris IA, Cuthbert A, de Steiger R, Lewis P, Graves SE: Practice variation in total hip arthroplasty versus hemiarthroplasty for treatment of fractured neck of femur in Australia. The bone \& joint journal 2019, 101-b(1):92-95.

19. Zhao Y, Fu D, Chen K, Li G, Cai Z, Shi Y, Yin X: Outcome of hemiarthroplasty and total hip replacement for active elderly patients with displaced femoral neck fractures: a meta-analysis of 8 randomized clinical trials. PloS one 2014, 9(5):e98071.

20. Hedbeck CJ, Enocson A, Lapidus G, Blomfeldt R, Tornkvist H, Ponzer S, Tidermark J: Comparison of bipolar hemiarthroplasty with total hip arthroplasty for displaced femoral neck fractures: a concise four-year follow-up of a randomized trial. The Journal of bone and joint surgery American volume 2011, 93(5):445-450.

21. Miller BJ, Callaghan JJ, Cram P, Karam M, Marsh JL, Noiseux NO: Changing trends in the treatment of femoral neck fractures: a review of the american board of orthopaedic surgery database. The Journal of bone and joint surgery American volume 2014, 96(17):e149.

22. Avery P, Baker R, Walton M, Rooker J, Squires B, Gargan M, Bannister G: Total hip replacement and hemiarthroplasty in mobile, independent patients with a displaced intracapsular fracture of the femoral neck: a seven- to ten-year follow-up report of a prospective randomised controlled trial. In: Journal of bone and joint surgery British volume. vol. 93; 2011: 1045-1048.

23. Tol MC, van den Bekerom MP, Sierevelt IN, Hilverdink EF, Raaymakers EL, Goslings JC: Hemiarthroplasty or total hip arthroplasty for the treatment of a displaced intracapsular fracture in active elderly patients: 12-year follow-up of randomised trial. The bone \& joint journal 2017, 99-b(2):250-254.

24. Burgers PT, Van Geene AR, Van den Bekerom MP, Van Lieshout EM, Blom B, Aleem IS, Bhandari M, Poolman RW: Total hip arthroplasty versus hemiarthroplasty for displaced femoral neck fractures in the healthy elderly: a meta-analysis and systematic review of randomized trials. International orthopaedics 2012, 36(8):1549-1560.

25. Liao L, Zhao J, Su W, Ding X, Chen L, Luo S: A meta-analysis of total hip arthroplasty and hemiarthroplasty outcomes for displaced femoral neck fractures. Archives of orthopaedic and trauma surgery 2012, 132(7):1021-1029.

26. Goh SK, Samuel M, Su DH, Chan ES, Yeo SJ: Meta-analysis comparing total hip arthroplasty with hemiarthroplasty in the treatment of displaced neck of femur fracture. The Journal of arthroplasty 2009, 24(3):400-406.

27. Higgins JPT. Green S e: Cochrane Handbook for Systematic Reviews of Interventions, version 5.1.0 (updated March 2011). Cochrane Collaboration website http://trainingcochraneorg 2011.

28. Liberati A, Altman DG, Tetzlaff J, Mulrow C, Gotzsche PC, loannidis JP, Clarke M, Devereaux PJ, Kleijnen J, Moher D: The PRISMA statement for reporting systematic reviews and meta-analyses of studies that evaluate healthcare interventions: explanation and 
elaboration. BMJ (Clinical research ed) 2009, 339:b2700.

29. Macaulay W, Nellans KW, lorio R, Garvin KL, Healy WL, Rosenwasser MP: Total hip arthroplasty is less painful at 12 months compared with hemiarthroplasty in treatment of displaced femoral neck fracture. HSS journal : the musculoskeletal journal of Hospital for Special Surgery 2008, 4(1):48-54.

30. Macaulay W, Nellans KW, Garvin KL, lorio R, Healy WL, Rosenwasser MP: Prospective randomized clinical trial comparing hemiarthroplasty to total hip arthroplasty in the treatment of displaced femoral neck fractures: winner of the Dorr Award. The Journal of arthroplasty 2008, 23(6 Suppl 1):2-8.

31. Blomfeldt R, Tornkvist H, Eriksson K, Soderqvist A, Ponzer S, Tidermark J: A randomised controlled trial comparing bipolar hemiarthroplasty with total hip replacement for displaced intracapsular fractures of the femoral neck in elderly patients. The Journal of bone and joint surgery British volume 2007, 89(2):160-165.

32. Keating JF, Grant A, Masson M, Scott NW, Forbes JF: Randomized comparison of reduction and fixation, bipolar hemiarthroplasty, and total hip arthroplasty. Treatment of displaced intracapsular hip fractures in healthy older patients. The Journal of bone and joint surgery American volume 2006, 88(2):249-260.

33. Baker RP, Squires B, Gargan MF, Bannister GC: Total hip arthroplasty and hemiarthroplasty in mobile, independent patients with a displaced intracapsular fracture of the femoral neck. A randomized, controlled trial. The Journal of bone and joint surgery American volume 2006, 88(12):2583-2589.

34. Narayan KK, George T: Functional outcome of fracture neck of femur treated with total hip replacement versus bipolar arthroplasty in a South Asian population. Archives of orthopaedic and trauma surgery 2006, 126(8):545-548.

35. Mouzopoulos G, Stamatakos M, Arabatzi H, Vasiliadis G, Batanis G, Tsembeli A, Tzurbakis M, Safioleas M: The four-year functional result after a displaced subcapital hip fracture treated with three different surgical options. International orthopaedics 2008, 32(3):367-373.

36. Giannini S, Chiarello E, Cadossi M, Luciani D, Tedesco G: Prosthetic surgery in fragility osteopathy. Aging clinical and experimental research 2011, 23(2 Suppl):40-42.

37. Dorr L, Glousman R, Hoy A, Vanis R, Chandler R: Treatment of femoral neck fractures with total hip replacement versus cemented and noncemented hemiarthroplasty. In: Journal of arthroplasty. vol. 1; 1986: 21-28.

38. Ravikumar KJ, Marsh G: Internal fixation versus hemiarthroplasty versus total hip arthroplasty for displaced subcapital fractures of femur-13 year results of a prospective randomised study. Injury 2000, 31(10):793-797.

39. Skinner P, Riley D, Ellery J, Beaumont A, Coumine R, Shafighian B: Displaced subcapital fractures of the femur: a prospective randomized comparison of internal fixation, hemiarthroplasty and total hip replacement. Injury 1989, 20(5):291-293.

40. Cadossi M, Chiarello E, Savarino L, Tedesco G, Baldini N, Faldini C, Giannini S: A comparison of hemiarthroplasty with a novel polycarbonate-urethane acetabular component for displaced intracapsular fractures of the femoral neck: a randomised controlled trial in elderly patients. The bone \& joint journal 2013,95-b(5):609-615.

41. Giannini S, Chiarello E, Cadossi M, Luciani D, Tedesco G: Prosthetic surgery in fragility osteopathy. Aging clinical and experimental research 2011, 23:40-42.

\section{Table 1}




\begin{tabular}{|c|c|c|c|c|c|c|c|c|c|c|}
\hline Author & Year & Location & $\begin{array}{c}\text { No } \\
, \mathrm{THA} / \mathrm{HA} \\
(\mathrm{P})\end{array}$ & $\begin{array}{c}\text { Number of male, } \\
\text { THA/HA }\end{array}$ & $\begin{array}{c}\text { Mean } \\
\text { age, } \\
\text { THA/HA } \\
\text { घy! }\end{array}$ & $\begin{array}{c}\text { THA } \\
\text { Details }\end{array}$ & HA Details & $\begin{array}{c}\text { Blood } \\
\text { loss } \square \\
\text { THA/HA } \\
(\mathrm{ml})\end{array}$ & $\begin{array}{c}\text { Operative } \\
\text { time[ } \\
\text { THA/HA } \\
\text { (min) }\end{array}$ & $\begin{array}{l}\text { Follow } \\
\text { up } \\
\text { (month) }\end{array}$ \\
\hline Keating & 2006 & Scotland & $69 / 69$ & $17(24.6 \%) / 15(21.7 \%)$ & $75.2 / 75.0$ & $\begin{array}{l}\text { Cemented } \\
\text { femoral }\end{array}$ & $\begin{array}{c}\text { Bipolar, } \\
\text { cemented }\end{array}$ & NA & NA & 24 \\
\hline $\begin{array}{l}\text { Avery\& } \\
\text { Baker }\end{array}$ & $\begin{array}{l}2011 \& \\
2006\end{array}$ & UK & $40 / 41$ & $8(20 \%) / 9(22.0 \%)$ & $74.2 / 75.8$ & $\begin{array}{c}\text { component } \\
\text { Cemented } \\
\text { acetabular } \\
\text { and } \\
\text { femoral } \\
\text { component }\end{array}$ & Cemented & NA & NA & $\begin{array}{l}86.4- \\
123.6\end{array}$ \\
\hline $\begin{array}{l}\text { Hedbeck\& } \\
\text { R.Blomfeldt }\end{array}$ & $\begin{array}{l}2011 \& \\
2007\end{array}$ & Sweden & $60 / 60$ & $13(22 \%) / 6(10 \%)$ & $80.5 / 80.7$ & $\begin{array}{l}\text { Cemented } \\
\text { acetabular } \\
\text { and } \\
\text { femoral } \\
\text { component }\end{array}$ & $\begin{array}{l}\text { Bipolar, } \\
\text { cemented }\end{array}$ & $460 / 320$ & $120 / 78$ & 48.4 \\
\hline $\begin{array}{l}\text { Macaulay\& } \\
\text { Macaulay }\end{array}$ & $\begin{array}{c}2008 \& \\
2008\end{array}$ & USA & $17 / 23$ & $10(59 \%) / 9(39 \%)$ & $82 / 77$ & NA & $\begin{array}{l}\text { Unipolar or } \\
\text { bipolar and } \\
\text { cemented } \\
\text { or } \\
\text { uncemented }\end{array}$ & NA & $89 / 82$ & 24 \\
\hline $\begin{array}{l}\text { Tol\&Van } \\
\text { den } \\
\text { Bekerom }\end{array}$ & $\begin{array}{c}2017 \& \\
2010\end{array}$ & Netherland & $115 / 137$ & $25(22 \%) / 22(16 \%)$ & $82.1 / 80.3$ & $\begin{array}{c}\text { Cemented } \\
\text { acetabular } \\
\text { and } \\
\text { femoral } \\
\text { component }\end{array}$ & $\begin{array}{l}\text { Bipolar, } \\
\text { cemented }\end{array}$ & NA & NA & $\begin{array}{l}98.8- \\
194.0\end{array}$ \\
\hline
\end{tabular}

NA: not available

Table1. Characteristics of the included studies.

Figures 


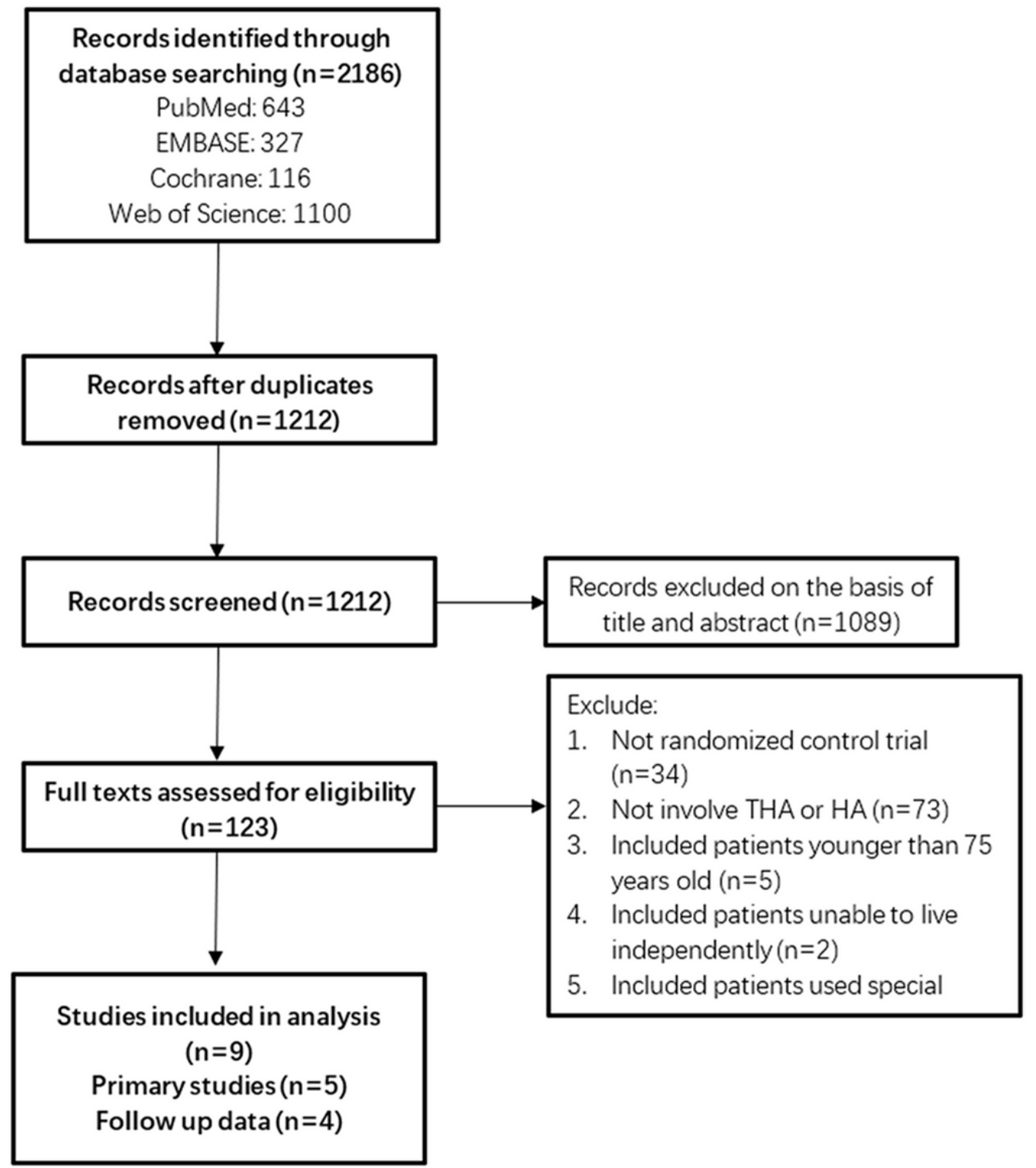

Figure 1

PRISMA flow chart of studies selection 


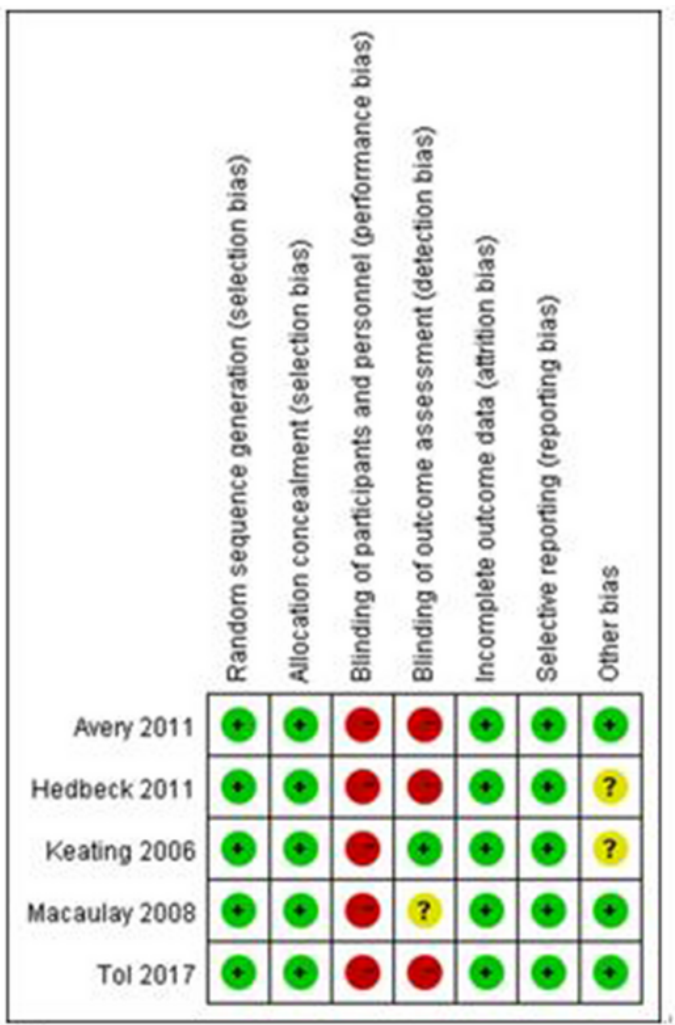

(a)

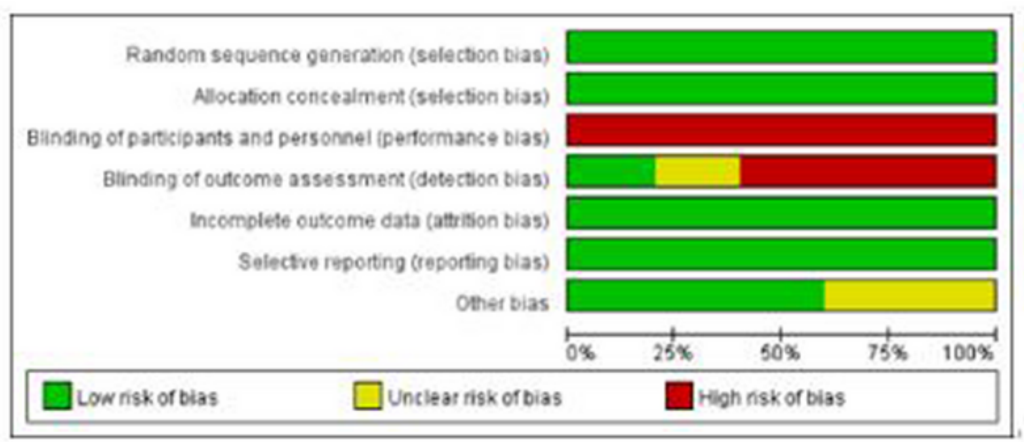

(b).

Figure 2

Risk of bias graph(a) and summary(b) of included studies

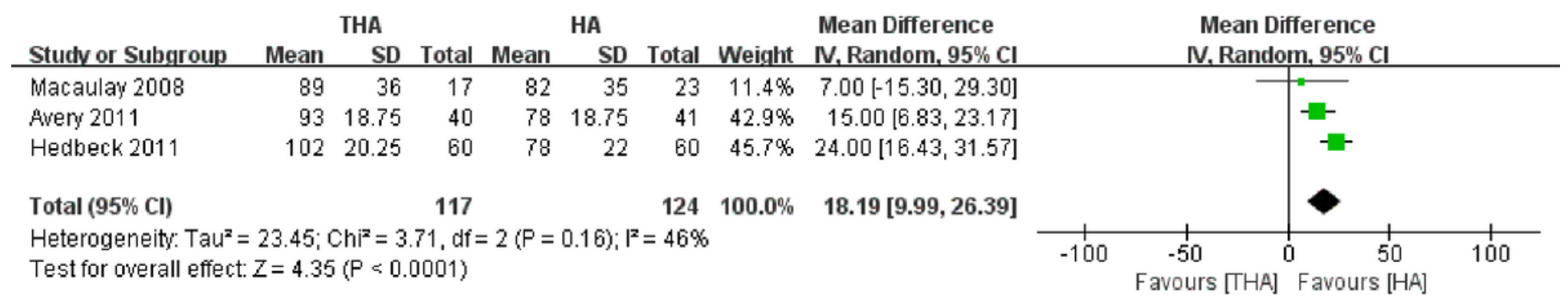

\section{Figure 3}

Forest plot of comparison of operative time 
THA

HA

Risk Ratio

Risk Ratio

Study or Subgroup Events Total Events Total Weight M-H, Fixed, $95 \% \mathrm{Cl}$

\subsection{1 within 6 months}

Avery 2011

Macaulay 2008

Tol 2017

Subtotal $(95 \% \mathrm{Cl})$

Total events

$0 \quad 40$

117

$5 \quad 115$

172

6

Heterogeneity: $\mathrm{Chi}^{2}=1.47, \mathrm{df}=2(\mathrm{P}=0.48) ; \mathrm{I}^{2}=0 \%$

Test for overall effect: $Z=1.34(P=0.18)$

\subsubsection{6 months to 5 years}

Avery 2011

Hedbeck 2011

Keating 2006

Macaulay 2008

Tol 2017

Subtotal $(\mathbf{9 5} \% \mathrm{Cl})$

Total events

Heterogeneity: $\mathrm{Chi}^{2}=6.47, \mathrm{df}=4(\mathrm{P}=0.17) ; \mathrm{I}^{2}=38 \%$

Test for overall effect: $Z=1.46(P=0.15)$

\subsection{4 more than 5 years}

Avery 2011

Tol 2017

Subtotal $(\mathbf{9 5} \% \mathrm{Cl})$

Total events

Heterogeneity: $\mathrm{Chi}^{2}=4.92, \mathrm{df}=1(\mathrm{P}=0.03) ; \mathrm{I}^{2}=80 \%$

Test for overall effect: $Z=0.66(P=0.51)$

\section{Total $(\mathbf{9 5} \% \mathrm{Cl})$}

Total events

Heterogeneity: $\mathrm{Chi}^{2}=15.82, \mathrm{df}=9(\mathrm{P}=0.07) ; \mathrm{I}^{2}=43 \%$

Test for overall effect: $Z=1.06(P=0.29)$

Test for subaroun differences: $\mathrm{Chi}^{2}=2.77 . \mathrm{df}=2(\mathrm{P}=0.25) . \mathrm{I}^{2}=27.7 \%$
$0.20[0.01,4.14]$

$0.27[0.03,2.11]$

$0.85[0.28,2.61]$

$0.54[0.22,1.33]$

M-H. Fixed, 95\% Cl

\section{Figure 4}

Forest plot of comparison of mortality rate

THA

HA

Events Total Events

Studv or Subgroup

$\begin{array}{lrrrr}\text { Hedbeck 2011 } & 6 & 60 & 5 & 60 \\ \text { Keating 2006 } & 4 & 69 & 5 & 69 \\ \text { Macaulay 2008 } & 8 & 17 & 9 & 23 \\ \text { Tol 2017 } & 28 & 115 & 23 & 137 \\ & & & & \\ \text { Total (95\% Cl) } & & 261 & & 289 \\ \text { Total events } & 46 & 42 \\ \text { Heterogeneity: Chi }=0.90, \mathrm{df}=3(\mathrm{P}=0.83) ; I^{2}=0 \% \\ \text { Test for overall effect: } Z=1.33(\mathrm{P}=0.18)\end{array}$

Test for overall effect: $Z=1.33(\mathrm{P}=0.18)$
$0.44[0.12,1.58]$

$1.21[0.66,2.24]$

$0.67[0.25,1.77]$

$0.75[0.31,1.84]$

$1.39[1.10,1.76]$

$1.17[0.95,1.44]$

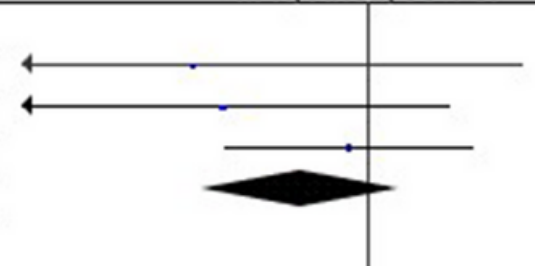

$0.63[0.37,1.09]$

$1.22[0.97,1.52]$

$1.07[0.87,1.31]$

$43.9 \%$

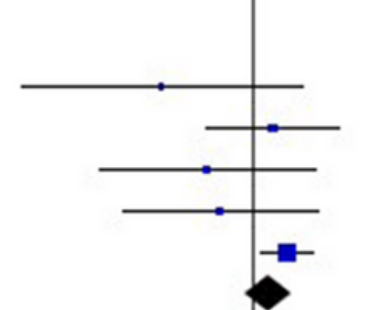

$1.08[0.93,1.25]$

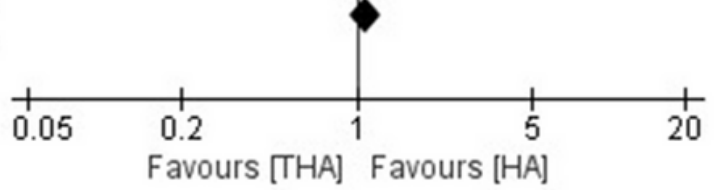

Figure 5

Forest plot of comparison of general complication 
THA

HA

Odds Ratio

Odds Ratio

Studv or Subgroup Events Total Events Total Weight M-H, Fixed, 95\% Cl

M-H, Fixed, 95\% Cl

Awery 2011

Hedbeck 2011

Keating 2006

Total $(95 \% \mathrm{Cl})$

Total events

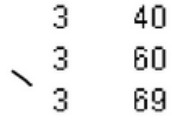

141

$41 \quad 16.1 \%$

$3.24[0.32,32.57]$

$1.53[0.25,9.48]$

$1.00[0.19,5.14]$

$1.54[0.54,4.41]$

Heterogeneity. Chi $=0.67, \mathrm{df}=2(P=0.72) ;{ }^{2}=0 \%$

Test for overall effect: $Z=0.80(P=0.42)$

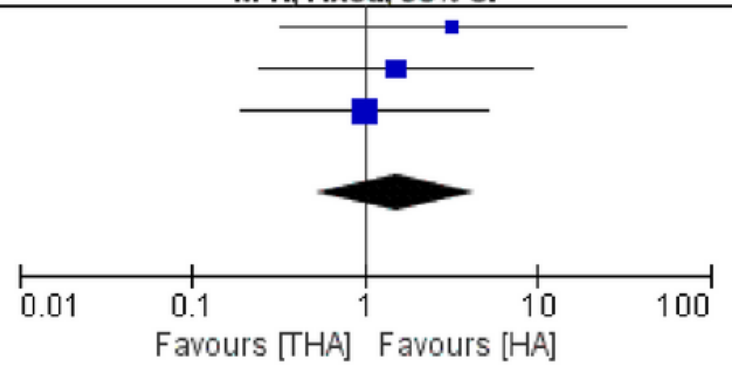

Figure 6

6 Forest plot of comparison of infection

THA

HA

Odds Ratio

Odds Ratio

Stuctv or Subgroup Events Total Events Total Weight M-H, Fixed, 95\% Cl

Awery 2011

Hedbeck 2011

Keating 2006

Total $(95 \% \mathrm{Cl})$

Total events

$\begin{array}{ll}4 & 40 \\ 0 & 60 \\ 5 & 69\end{array}$

$34152.5 \%$

$60 \quad 29.3 \%$

$1 \quad 69 \quad 18.3 \%$

$1.41[0.29,6.73]$

$0.33[0.01,8.21]$

$5.31[0.60,46.71]$

$170 \quad 100.0 \%$

169

9
5

Heterogeneity: $\mathrm{Chi}^{2}=2.12, \mathrm{df}=2(\mathrm{P}=0.35) ; \mathrm{I}^{2}=6 \%$

Test for overall effect: $Z=1.07(P=0.28)$
$1.80[0.61,5.30]$

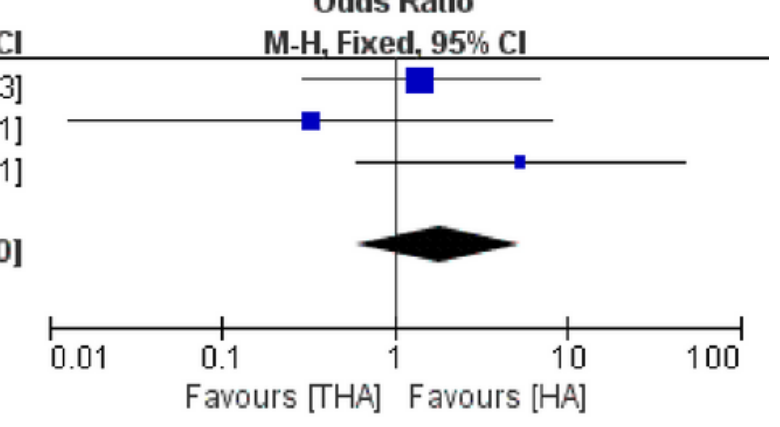

Figure 7

Forest plot of comparison of VTE

THA

HA

Odds Ratio

Odds Ratio

Studv or Subgroup Events Total Events Total Weight M-H, Fixed, 95\% CI

Avery 2011

Hedbeck 2011

Total $(95 \% \mathrm{Cl})$

$\begin{array}{ll}0 & 40 \\ 1 & 42\end{array}$

40

82

$141 \quad 40.3 \%$

$0.33[0.01,8.43]$

$0.98[0.06,16.14]$

Total events

12

Heterogeneity: $\mathrm{Ch}^{2}=0.24, \mathrm{df}=1(\mathrm{P}=0.62) ; \mathrm{l}^{2}=0 \%$

Test for overall effect: $Z=0.50(P=0.62)$
$0.59[0.08,4.60]$

$82100.0 \%$

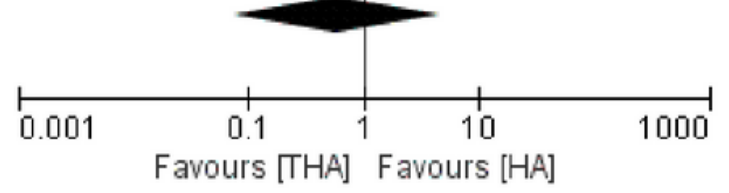

Figure 8

Forest plot of comparison of peri-prosthetic fracture

\section{THA}

HA

Risk Ratio

Studv or Subgroup Events Total Events Total Weight M-H, Fixed, 95\% Cl

Avery 2011

Hedbeck 2011

Tol 2017

Total $(95 \% \mathrm{Cl})$

Total events

$0 \quad 32$

$0 \quad 42$

$\begin{array}{lll}21 & 36 & 51.9 \%\end{array}$

1115

537

$14 \quad 133$

$14.9 \%$

$33.2 \%$

$206100.0 \%$

Heterogeneity: $\mathrm{Chi}^{2}=0.52, \mathrm{df}=2(\mathrm{P}=0.77) ; \mathrm{I}^{2}=0 \%$

Test for overall effect: $Z=4.09$ ( $P \leq 0.0001)$
$0.03[0.00,0.41]$

$0.08[0.00,1.41]$

$0.08[0.01,0.62]$

$0.05[0.01,0.22]$

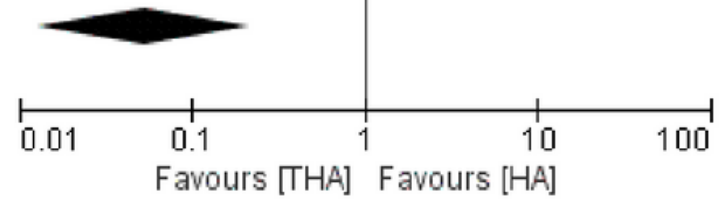

Figure 9

Forest plot of comparison of erosion 
THA

HA

Odds Ratio

Odds Ratio

Study or Subgroup

Events Total Events Total Weight $\mathrm{M}-\mathrm{H}$, Fixed, $95 \% \mathrm{Cl}$

M-H, Fixed, 95\% Cl

1.23.1 within 3 years

$\begin{array}{lrrrrrr}\text { Avery 2011 } & 3 & 40 & 0 & 41 & 14.2 \% & 7.75[0.39,154.96] \\ \text { Hedbeck 2011 } & 0 & 60 & 0 & 60 & & \text { Not estimable } \\ \text { Keating 2006 } & 3 & 69 & 2 & 69 & 59.9 \% & 1.52[0.25,9.41] \\ \text { Macaulay 2008 } & 1 & 17 & 0 & 23 & 12.3 \% & 4.27[0.16,111.52] \\ \text { Tol 2017 } & 5 & 115 & 0 & 137 & 13.6 \% & 13.69[0.75,250.23] \\ \text { Subtotal (95\% Cl) } & & 301 & & 330 & \mathbf{1 0 0 . 0} \% & \mathbf{4 . 4 0}[\mathbf{1 . 3 5}, \mathbf{1 4 . 3 7 ]} \\ \text { Total events } & 12 & & 2 & & & \end{array}$

Heterogeneity: $\mathrm{Chi}^{2}=2.03, \mathrm{df}=3(\mathrm{P}=0.57) ; \mathrm{I}^{2}=0 \%$

Test for overall effect: $Z=2.45(P=0.01)$

1.23.2 more than 3 years

$\begin{array}{llllll}\text { Hedbeck } 2011 & 0 & 42 & 0 & 41 & \text { Not estimable } \\ \text { Tol } 2017 & 0 & 18 & 0 & 32 & \text { Not estimable } \\ \text { Subtotal }(95 \% \mathrm{Cl}) & & 60 & & 73 & \text { Not estimable } \\ \text { Total events } & 0 & & 0 & & \end{array}$

Heterogeneity: Not applicable

Test for overall effect: Not applicable

$\begin{array}{lllllll}\text { Total }(95 \% \mathrm{Cl}) & & 361 & & 403 & 100.0 \% & 4.40[1.35,14.37] \\ \text { Total events } & 12 & & 2 & & & \end{array}$

Heterogeneity: $\mathrm{Chi}^{2}=2.03, \mathrm{df}=3(\mathrm{P}=0.57) ; \mathrm{I}^{2}=0 \%$

Test for overall effect: $Z=2.45(P=0.01)$

Test for subaroun differences: Not annlicable

Figure 10

Forest plot of comparison of re-operation

HA

Odds Ratio

Odds Ratio

Studv or Subgroup Events Total Events Total Weight M-H, Fixed, $95 \% \mathrm{Cl}$ 1.23.1 within 3 years

Avery 2011

Hedbeck 2011

Keating 2006

Macaulay 2008

Tol 2017

Subtotal $(95 \% \mathrm{Cl})$

340

$40 \quad 0$

41

$14.2 \%$

$7.75[0.39,154.96]$

060

369

69

060

269

$59.9 \%$

Not estimable

$1 \quad 17$

$5 \quad 115$

$0 \quad 23$

$12.3 \%$

$1.52[0.25,9.41]$

301

137

$330 \quad 100.0 \%$

$13.69[0.75,250.23]$

4.40 [1.35, 14.37]

Total events

12

2

Heterogeneity: $\mathrm{Chi}^{2}=2.03, \mathrm{df}=3(\mathrm{P}=0.57) ; \mathrm{I}^{2}=0 \%$

Test for overall effect: $Z=2.45(P=0.01)$

1.23.2 more than 3 years

$\begin{array}{llllll}\text { Hedbeck } 2011 & 0 & 42 & 0 & 41 & \text { Not estimable } \\ \text { Tol } 2017 & 0 & 18 & 0 & 32 & \text { Not estimable } \\ \text { Subtotal }(95 \% \mathrm{Cl}) & & 60 & & 73 & \text { Not estimable } \\ \text { Total events } & 0 & & 0 & & \end{array}$

Heterogeneity: Not applicable

Test for overall effect: Not applicable

Total $(95 \% \mathrm{Cl})$

361

$403100.0 \%$

$4.40[1.35,14.37]$

Total events

$12 \quad 2$

Heterogeneity: $\mathrm{Chi}^{2}=2.03, \mathrm{df}=3(\mathrm{P}=0.57) ; \mathrm{I}^{2}=0 \%$

Test for overall effect: $Z=2.45(P=0.01)$

Test for subaroun differences: Not anplicable

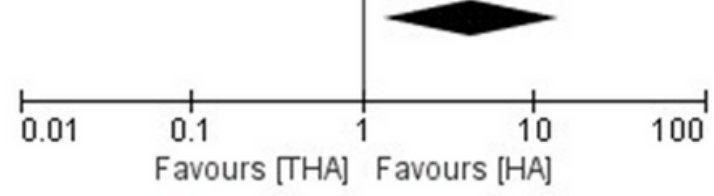

Figure 11

Forest plot of comparison of re-operation, including patients with painful symptoms but without re-operation. 
THA

HA

Odds Ratio

Odds Ratio

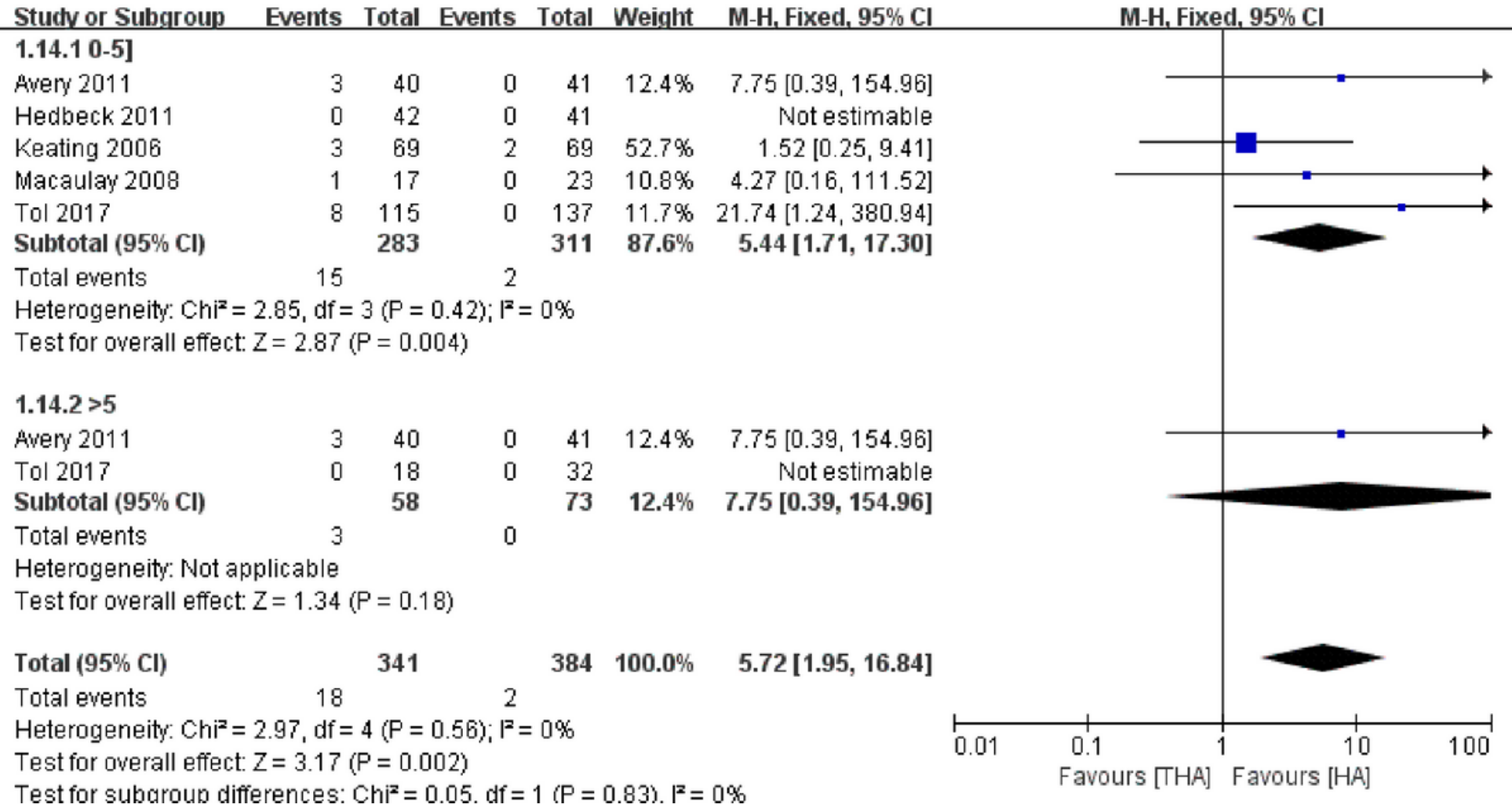

Figure 12

Forest plot of comparison of dislocation

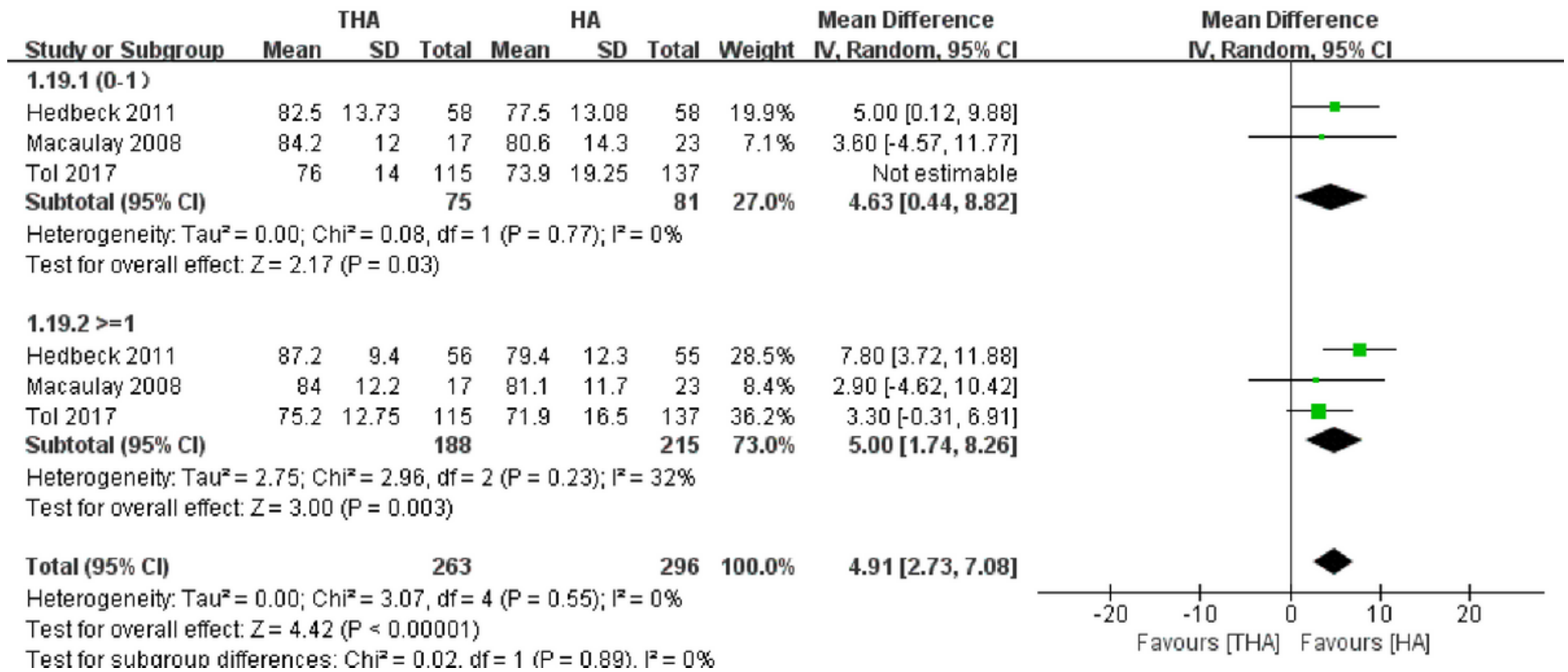

Figure 13

Forest plot of comparison of total Harris Hip Score 
THA HA Mean Difference

Mean Difference

Study or Subgroup Mean SD Total Mean SD Total Weight IV, Fixed, 95\% CI $1.15 .1(0-1]$

$\begin{array}{lrrrrrrrr}\text { Hedbeck 2011 } & 42 & 4.5 & 58 & 40 & 6.6 & 58 & 21.0 \% & 2.00[-0.06,4.06] \\ \text { Tol 2017 } & 40 & 6 & 115 & 37.5 & 8.5 & 137 & 27.5 \% & 2.50[0.70,4.30] \\ \text { Subtotal (95\% Cl) } & & & \mathbf{1 7 3} & & & \mathbf{1 9 5} & \mathbf{4 8 . 4} \% & 2.28[0.93,3.64]\end{array}$

Heterogeneity: $\mathrm{Ch}^{\mathbf{2}}=0.13, \mathrm{df}=1(\mathrm{P}=0.72) ; \mathrm{I}^{\mathbf{2}}=0 \%$

Test for overall effect: $Z=3.31(P=0.0009)$

1.15.2 >1

$\begin{array}{lrrrrrrrr}\text { Hedbeck 2011 } & 42.7 & 3 & 52 & 37.8 & 6.2 & 49 & 24.1 \% & 4.90[2.98,6.82] \\ \text { Tol 2017 } & 40.1 & 6 & 115 & 38.6 & 8.5 & 137 & 27.5 \% & 1.50[-0.30,3.30] \\ \text { Subtotal (95\% Cl) } & & & \mathbf{1 6 7} & & & \mathbf{1 8 6} & \mathbf{5 1 . 6 \%} & \mathbf{3 . 0 9}[\mathbf{1 . 7 8 , 4 . 4 0}]\end{array}$

Heterogeneity: $\mathrm{Chi}^{2}=6.43, \mathrm{df}=1(\mathrm{P}=0.01) ; \mathrm{I}^{2}=84 \%$

Test for overall effect: $Z=4.62$ ( $P<0.00001$ )

Total $(95 \% \mathrm{Cl})$

340

Heterogeneity: $\mathrm{Ch}^{2}=7.26, \mathrm{df}=3(\mathrm{P}=0.06) ; \mathrm{I}^{2}=59 \%$

Test for overall effect: $Z=5.62(P=0.00001)$

Test for subaroun differences: $\mathrm{Chi}^{2}=0.70 . \mathrm{df}=1(\mathrm{P}=0.40) . \mathrm{I}^{2}=0 \%$
$381100.0 \% \quad 2.70[1.76,3.64]$

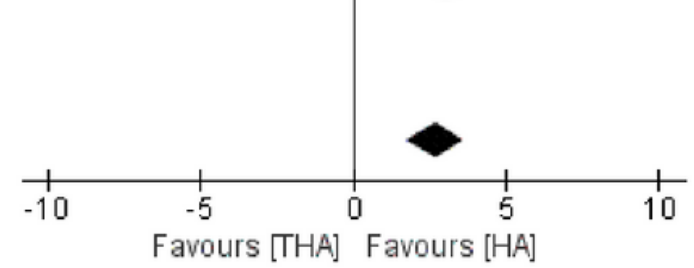

\section{Figure 14}

Forest plot of comparison of Harris Hip pain Score

THA HA

Studv or Subgroup

\subsection{1 (0-1]}

Hedbeck 2011

Tol 2017

Subtotal $(95 \% \mathrm{Cl})$

Heterogeneity: $\operatorname{Tau}^{2}=2.50 ; \mathrm{Chi}^{2}=2.25$,

Test for overall effect: $Z=0.92(P=0.36)$

\subsection{2 $>1$}

Hedbeck 2011

Tol 2017

Subtotal $(95 \% \mathrm{Cl})$ $\begin{array}{ll}35.7 & 8.7 \\ 18.3 & 7.4\end{array}$

78

31.39 $16.4 \quad 8.8$

$\begin{array}{ll}49 & 22.7 \% \\ 32 & 15.6 \% \\ 81 & 38.2 \%\end{array}$

$70, d f=1(P=0.40) ;\left.\right|^{2}=0 \%$

Heterogeneity: Tau $^{2}=0.00 ; \mathrm{Chi}^{2}=0.72, \mathrm{~d}$
Test for overall effect: $Z=2.45(P=0.01)$

Total $(95 \% \mathrm{Cl})$

241

$273 \quad 100.0 \%$

Heterogeneity: $\operatorname{Tau}^{2}=1.78 ; \mathrm{Chi}^{2}=4.98, \mathrm{df}=3(\mathrm{P}=0.17) ; \mathrm{I}^{2}=40 \%$

Test for overall effect: $Z=1.99(P=0.05)$

Test for subaroun differences: $\mathrm{Ch}^{2}=1.06 . \mathrm{df}=1(\mathrm{P}=0.30) . \mathrm{I}^{2}=5.8 \%$
Mean Difference

, Random, $95 \% \mathrm{Cl}$

$3.10[-0.12,6.32]$

$0.10[-2.13,2.33]$

$1.37[-1.54,4.27]$

\section{Figure 15 \\ Figure 15}

$4.40[0.90,7.90]$

$1.90[-2.68,6.48]$

$3.48[0.70,6.26]$
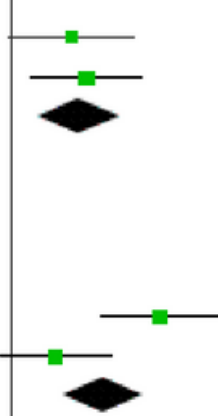

Forest plot of comparison of Harris hip function score

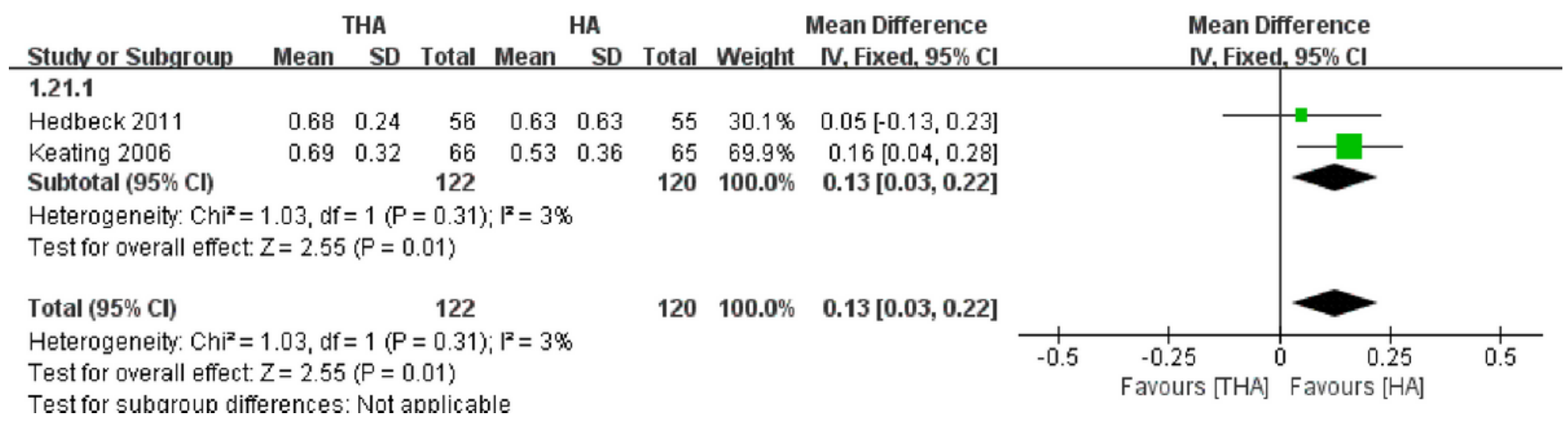


Figure 16

Forest plot of comparison of Eq-5D index score

\begin{tabular}{|c|c|c|c|c|c|c|c|c|}
\hline \multirow[b]{2}{*}{ Stuctv or Subgroup } & \multicolumn{3}{|c|}{ THA } & \multicolumn{2}{|r|}{ HA } & \multicolumn{3}{|r|}{ Mean Difference } \\
\hline & Mean & SD & Total & Mean & SD & Total & Weight & IV, Fixed, $95 \% \mathrm{Cl}$ \\
\hline Macaulay 2008 & 7.7 & 5.5 & 17 & 5.4 & 2.8 & 23 & $77.0 \%$ & $2.30[-0.55,5.15]$ \\
\hline Tol 2017 & 18.4 & 20.5 & 115 & 17.1 & 21.75 & 137 & $23.0 \%$ & $1.30[-3.93,6.53]$ \\
\hline Total $(95 \% \mathrm{Cl})$ & & & 132 & & & 160 & $100.0 \%$ & $2.07[-0.43,4.57]$ \\
\hline
\end{tabular}

Heterogeneity: $\mathrm{Chi}^{2}=0.11, \mathrm{df}=1(\mathrm{P}=0.74) ; \mathrm{I}^{2}=0 \%$

Test for overall effect: $Z=1.62(P=0.11)$

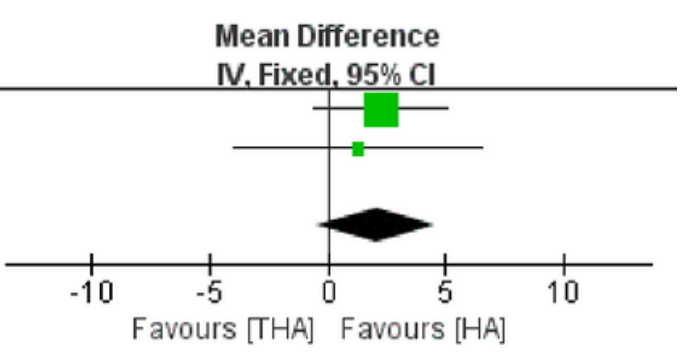

Figure 17

Forest plot of comparison of hospital stay

\section{Supplementary Files}

This is a list of supplementary files associated with this preprint. Click to download.

- AppendixA.docx

- PRISMA2009checklist.doc 